\title{
EXPERIENCE AND MATHEMATICAL KNOWLEDGE
}

\author{
RODOLFO GAETA
}

\begin{abstract}
According to a very common view, the main tenet of empiricism is the conviction that all human knowledge derives from sensory experience. But classic philosophers representing empiricism hold that mathematical knowledge is a priori. Mill intended to demonstrate that the laws of arithmetic and geometry have inductive origins. But Frege and others authors showed that Mill's arguments were wrong. Benacerraf held that, since mathematical objects are abstract entities, they could not have any causal relationship with human beings, so they cannot be known by us. On the other hand, biology and psychology show that in animals and human creatures we can find innate behaviours, in accordance with the theory on natural selection. Experiments performed by Wynn and by other psychologists strongly support that very young babies can determine the results of simple arithmetical operations without any previous learning. We conclude that there are convincing reasons to accept the rationalist thesis about the a priori character of mathematical knowledge.
\end{abstract}

Keywords: Experience; mathematical knowledge; innateness; empiricism; rationalism.

\section{Introduction}

While rationalists have argued that knowledge contains innate elements, empiricists would be very satisfied if it could be proved that absolutely all human knowledge could be justified by sensory experience. But mathematics has resisted subordinate itself to that desire. Few have been the empiricists who really tried to fulfil that desire, and I think they have failed. I intend to make a few brief references to some classic episodes of this story and I will try to show that there are reasons to link mathematical knowledge with something more than experience.

\section{Sensations, ideas and numbers in English empiricism}

According to Locke, experience recognizes two sources: sensation and reflection. Sensation unfolds ideas that depend on the properties of the entities of the external world. Reflection, on the other hand, consists of the gaze that the mind directs on itself and observes its own actions on the ideas it has (Locke 1690, Book II, Chapter VI, 1). But the idea of number or unit is so basic that it seems to transcend this distinction to become a necessary companion or a prerequisite of all the others:

Amongst all the ideas we have, as there is none suggested to the mind by more ways, so there is none more simple, than that of unity, or one: it has no

Principia 21(2): 209-222 (2017).

Published by NEL — Epistemology and Logic Research Group, Federal University of Santa Catarina (UFSC), Brazil. 
shadow of variety or composition in it: every object our senses are employed about; every idea in our understandings; every thought of our minds, brings this idea along with it. And therefore it is the most intimate to our thoughts, as well as it is, in its agreement to all other things, the most universal idea we have. For number applies itself to men, angels, actions, thoughts; everything that either doth exist, or can be imagined. (Locke 1690, Book II, Chapter XVI, §1)

Mathematical operations, such as adding one by one and repeating this operation, give rise to the complex ideas of the other quantities. Locke discards the usefulness of axioms and describes the appreciation of mathematical truths in terms of the indubitable conviction that accompanies the perception of agreement or disagreement between ideas. Whoever has the ideas of the respective numbers cannot ignore that $1+2+3=6$, just as it is impossible for the same thing to be and not be (Locke 1690: 968). Locke considers that intuitive knowledge, the direct comparison of some ideas with others, constitutes the highest degree of knowledge because it is completely true without the need of any proof. What is decisive for mathematical knowledge is not experience in the ordinary sense, sensation, but a peculiar purely mental internal experience. Therefore, mathematical knowledge is a priori knowledge. The fact that it arises from a relationship between ideas seems to be related to the kind of truths that later were called "analytical", although they are not characterized exactly as Kant will describe them or as the logical empiricists will later define them. Notwithstanding that character, they have a factual scope. They inform about certain properties of real objects, for what is known about mathematical objects in the mind will also be true "when they have real existence in matter" (Locke 1690, Book IV, Chapter IV, §6). Locke denied the possibility of innate ideas; but as for mathematical knowledge, I do not find significant differences between his convictions and those of any rationalist.

Hume's case is similar in that respect. He also rejected the widespread belief that reason allowed for a priori knowledge in the field of morality or physics (Hume 1751, $\S 36$ n.). But he maintained that the situation is completely opposite in the case of geometry, arithmetic, algebra and any statement that is true according to intuition or demonstration.

Propositions of this kind can be discovered purely by thinking, with no need to attend to anything that actually exists anywhere in the universe. The truths that Euclid demonstrated would still be certain and self-evident even if there never were a circle or triangle in nature (Hume 1748, Section 4, Part 1).

Consequently, those disciplines constitute unequivocal manifestations of necessary a priori knowledge, because they are based on relations of ideas and not on impressions, which only reach to establish contingent connections and are limited to matters of fact.

Principia 21(2): 209-222 (2017). 


\section{Mathematical knowledge in Mill's radical empiricism}

In contrast to the singular role that Locke and Hume attribute to mathematical knowledge, Mill's position is framed in the popular image that shows empiricism as opposed to a priori knowledge. Mill classifies propositions into two types, verbal and real. The former refers to the conformity or disagreement of the use of terms with respect to linguistic conventions and says nothing about the characteristics of things. They could only provide linguistic information and only in that field would they be true or false. Actually — as a foretaste of Quine's questioning of the possibility that there may be truths by convention - Mill maintains that verbal propositions "strictly speaking are not susceptible to truth or falsity” (Mill 1843, I.VI. §1- I.VI. §4).

As for the laws of mathematics and logic, including the principle of non-contradiction and the principle of excluded middle, according to Mill, they are experimental truths because they have arisen from observation. Its greater comparative strength with respect to other beliefs comes from having broader and varied inductive elements of judgment. Mill believes that the evidence and the infallibility of mathematical propositions advocated by the intuitionist philosophers are illusory. For him, the only genuine inferences are the inductive ones; from the point of view of its strictly cognitive value, deductions do not add anything to the information. But the version of the induction exposed by Mill departs from the traditional formula: "infer the general from the particular". Since general premises can only be based primarily on inductions and given their purely pragmatic value, they are logically dispensable; Inference leads, then, from the fact that a number of cases in which it is verified that such and such individuals have a certain property to the conclusion that some other individual of a similar kind previously not considered also has that property. You do not need to formulate the premise that all men are mortal to conclude that Socrates is mortal: the same particular premises that led to the general conclusion lead directly to the singular conclusion that Socrates is mortal.

Mathematical propositions seem to be necessary because they are deduced from the axioms. But the later, in turn, are established as generalizations from particular cases repeatedly experienced. That two straight lines do not delimit a surface is something that we can see each time we draw two straight lines. According to Mill, not even the inconceivability of the opposite situation would be a sign of its a priori validity, because the impossibility of conceiving something is not a proof of its non-existence. Arithmetic is also based on observation. A group of four elements, for example, could be distributed in two groups, each composed of two members, and also the group of four elements can be reorganized into one having one element and another composed of three elements; thus we come to believe that $3+1=4$ and that $2+2=4$.

Principia 21(2): 209-222 (2017). 


\section{Mathematical knowledge and psychology}

The fact that mathematical operations are mainly mental performances rather than physical manipulations has led us to think that Mill reduced mathematics to psychology (Schneewind 1972, p.316). But to say that mathematics is reduced to psychology is to fall into a confusion. It is true that empiricists, or at least those empiricists who believe that ideas plays a central role in knowledge, focus on them to expose their theory of knowledge; and as long as ideas are related to the mind, it is tempting to think that the whole thing refers to mental, or in other words, psychological entities. But this conclusion deserves some clarification. Physicists would normally say that they study properties of the natural world and do not practice psychology although, according to the empiricists, the knowledge that physicists themselves or anyone gain about the world require the intervention of sensations and ideas. Establishing the mechanisms and processes that make it possible for these sensations and ideas to be formed is one of the subject matters of psychology and other conjugated disciplines. Considered in this way, psychology and other sciences associated with it play the role of describing and perhaps explaining how ideas come to be formed in the minds of people. Different is the case, in principle, of epistemology - unless we adopt a criterion of complete and absolute naturalization - because it must be taken into account an aspect that does not appear in the descriptions and explanations just mentioned. I mean justification or some alternative notions that play an analogous role concerning knowledge, as reliability or guarantee of a belief. Justification involves an irreducibly normative, prescriptive or evaluative component that is not included in the descriptive or explanatory tasks that psychology and the other mentioned sciences carry out. Without denying the relevance of elements provided by several sciences for the formulation of an epistemological theory, to reach the conclusion that Mill's is a psychological theory of mathematical knowledge seems to me to be equivocal or erroneous even when he himself came to believe it at times. Actually, he sometimes maintains that logic and mathematics depend on psychology, but on other occasions he denies it (Cf. Kusch 2015).

I wish to add some more comments. 1) Dependency may mean the convenience or even the need of employing results of psychological research, but it does not imply a reduction of epistemology to psychology. 2) The type of psychological reflections that Mill undertakes is introspective, rather than objective or experimental in the current sense of the term. 3) As long as they remain within the limits of the conscience of the knowing subject, they run the risk of being a priori hypothesis, such as those that empiricists usually like to reject. 4) His treatment of logic, his recognition of mathematics as legitimate knowledge and his pleading for analogical induction as the only authentic mode of inferential knowledge engage him with a normative dimension, which would be out of place if his tenets were to be considered as a psychological

Principia 21(2): 209-222 (2017). 
explanation. An example of psychological observation could be the verification that people often reason in a certain way - inferring the antecedent from the consequent of a conditional statement for example - but if we say that when people reason that way they are committing a fallacy we slip from psychology to logic.

Then, Mill's main purpose was to legitimize mathematical knowledge, which finds its justification in the observation of the external world and in the employment of induction, so that, according to his doctrine, mathematical propositions are not analytic, nor a priori, nor necessarily true, but useful and reliable anyway. And that constitutes an epistemological theory rather than a psychological one.

\section{Frege's antipsychologism and the independence of numbers}

According to the arguments we have given, the alleged reduction of mathematics to psychology would seem to contain certain confusions. I have leaned towards a reading of Mill's empiricism that does not make mathematics a part of psychology. But, anyway, Frege understood it that way and formulated several arguments to reject that claim, which was shared by other authors. First, Frege points out the need to distinguish two meanings of the term "idea". According to the first, in a properly psychological sense, the word denotes the subjective and idiosyncratic content of individual minds. According to the second, in a completely different interpretation, it has an objective meaning and refers to abstract entities. The ideas that belong to mathematical knowledge, then, are objective; they are abstract entities in themselves and denote, in turn, certain abstract entities, the numbers, which constitute the subject matter of mathematics. In Frege's theory, numbers are entities in a strict sense, objects, according to his terminology; they exist independently of the ideas that someone may come to conceive about numbers, independently of any material thing or matter of fact. Numbers are not signs and do not refer to anything. As they are objects, numbers are not properties of any kind, and consequently, they cannot be attributes of aggregates of things (Frege 1884). The attempt to explain mathematical calculations in terms of physical or mental operations related to aggregates of things is also discarded, since material aggregates do not offer characteristic ways to be divided or regrouped. Induction as a foundation of arithmetical truths is also discarded by Frege. He believes that, on the contrary, inductions depend, in any case on mathematics, namely on statistics.

By describing numbers in this way, Frege resolutely adopts a platonist realism. He does not deny that experience intervenes as an element for acquiring mathematical knowledge, but as much as it refers to numbers, it is a knowledge whose justification is totally independent of experience. For this knowledge is not based on the observation of any fact, much less in any inductive procedure similar to those advocated

Principia 21(2): 209-222 (2017). 
by Mill. At this point Frege's logicism, his formidable elaboration to show that truths about numbers are deduced from the laws of pure logic plays a key role. The success that this enterprise would have meant exposing the failure of Kant's theory, which had described mathematical judgments as synthetic a priori truths founded on pure intuitions. According to Frege, on the other hand, the validity of truths about numbers does not arise from any kind of intuition but from logic itself, which in turn does not require any justification. The arithmetical truths, then, turn out to be analytical, because they are deduced from logical truths. And a priori because the latter are justified by themselves.

\section{From psychology to calligraphy?}

Mathematicians usually speak of numbers as if they were things that exist by themselves and it is reasonable to attribute to most mathematicians a kind of adherence to a "natural ontological attitude" akin to the mathematical realism defended by Frege. But even when this position exhibits an honourable philosophical tradition, the identification of numbers with abstract entities produces resistance in many mentalities. We have seen that some philosophers identify numbers with mental contents and others seek their origin in properties of the physical world. On the other hand, in ordinary language we often use the word "number" when we really want to say something about the signs that represent them ("Roman numbers", "Arabic number", instead of "Roman numerals" and "Arabic numerals"). But it is unlikely that a mathematician or a philosopher, when they are expressing themselves in a rigorous way, confuses numerals with numbers. However, Hilbert characterized numbers in such a way that, at first glance, it falls into that identification. Indeed, he has come to write:

En mathématiques en particulier, l'objet de notre examen ce sont les signes concrets euxmêmes dont la forme nous apparaît immédiatement avec évidence, conformément à notre position fondamentale, et demeure parfaitement reconnaissable. (Quoted by Ladriére 1957, p.3. My italics)

But I have said that at first glance Hilbert identified numbers with their numerals because there are several reasons that invite us not to interpret his words in a literal way.

In the first place, if the concrete signs are material entities that occupy certain places in space during certain times, it is unlikely that they constitute the object of study of a pure science as oriented towards abstraction as mathematics. Even the factual sciences - except those interested in historical or individual processes privilege the consideration of common characteristics of the entities that constitute their subject matter and leave aside their concrete circumstances.

Principia 21(2): 209-222 (2017). 
Second, there are Hilbert's formulations that explicitly exclude that the objects dealt with by mathematicians are concrete things qua particular entities:

Pour moi — et en cela je m'oppose totalement à Frege et à Dedekind — les objets de la théorie des nombres sont les signes eux-mêmes, dont nous pouvons reconnaître la forme en toute generalité et en toute sécurité, indépendamment des circonstances de lieu et de temps, de toutes les conditions particulières de leur présentation aussi bien que des différences insignifiantes qui peuvent affecter leur tracé. (Quoted by Ladriére 1957, p.4. My italics).

It is true that Hilbert is referring to signs, but we can pay attention to the fact that such signs are taken into account as a way of considering its general character and with independence of its concrete traits.

Third, it is also true that Hilbert insists that the objects of mathematics are the signs, and there are indications that when he said this he had in mind what could be the primitive manifestation of graphics in mathematics, marks or strokes in the style of which represents the number one in Roman notation and a series of those strokes to express the following numbers. But if the strokes are taken as concrete things, each one that is written is different from the others, even in the same expression composed by a row of several of them. This explanation would be adequate if Hilbert were referring to type signs and not to its tokens. The problem arises when we notice that type signs are abstract entities, not concrete things. So, as much as Hilbert was referring to numerals as type signs he could not avoid committing himself to abstract entities (Bostock 2009, p.174).

In short, Hilbert shared Frege's antipsychologism but rejected the platonist solution and for that reason he believed that numerals — whose tokens are physically perceptible, concrete things and not abstract ideas - were good candidates to endow mathematics with an ontological counterpart. But as long as numerals are taken as type signs, then they are abstract entities and Hilbert indirectly adhered to a form of mathematical realism that implies the existence of abstract objects, a central thesis of platonism. This conclusion invites a final comment. The interpretation we have given presents Hilbert far removed from the popular image of a formalist who identifies mathematical theories with purely syntactic systems. According to such formalistic view, it would not be pertinent to discuss what the object of a mathematical system is or whether what it says is true or false. Those issues were however of crucial importance to Hilbert:

Qu'en serait-il de la vérité de notre savoir, de l'existence et du progrès de la science s'il n'y avait au moins en mathématiques une vérité solide? (Quoted by Ladriére 1957, p.1).

Principia 21(2): 209-222 (2017). 


\section{The return of psychology?}

Brouwer's intuitionism has been one of the most striking responses generated by the crisis that the appearance of paradoxes in set theory had produced. I will not take into account, however, the modifications that intuitionism encouraged with respect to the method and content of mathematics or the underlying logic. I will only make some brief mentions to some semantic, epistemological and ontological aspects of intuitionism. Lemhoff points out that at age 24 Brouwer had written a book, Life, Art and Mysticism, whose solipsistic ideas presaged the future mathematical philosophy of its author. Mathematical entities, according to Brouwer, do not exist in a world independent of the thinking subject. They are built by him and start its existence, precisely at the moment that this construction takes place. This situation gives to numbers a temporal dimension generally considered alien to this type of entity. Time also plays another role; in this case, a primary one, in the constitution of numbers by the subject, because it is the direct mental perception of the succession of instants (in a way that recalls Kant's doctrine about the issue) which leads to the number 1 , the number 2 , and so on. This is how intuition acts and fully guarantees the truth proper to mathematical objects. Signs, language, have a secondary role, since their function is to allow intercommunication between mathematicians, so that they can share the same ideas. There are differences between the interpreters about whether the subject who creates the numbers that Brouwer referred to was an ideal subject or a kind of transcendental subject and whether, as many believe, it corresponds to include Brouwer's view as a kind of mathematical psychologism. According to Lemhoff, he did not think he was doing psychology. And in line with my previous comments about other supposed representatives of mathematical psychologism, I am inclined to agree with Lemhoff on this point.

\section{From psychology to semantics}

The great transformations produced in mathematics, in physics and in logic during the nineteenth and early twentieth century were accompanied by three typical attitudes: the exaltation of science, the sympathy for epistemological conventionalism, and the famous "linguistic turn". This combination provided the logical empiricists with the elements to rethink the relationship between experience and mathematics. Driven by their desire to resist all forms of metaphysics, they rejected the possibility of synthetic a priori judgments and reformulated the Kantian approach. They drew a separation between what they called the formal sciences and the factual sciences, and only in the case of the formal sciences they left room for a priori knowledge, although it is expressed by analytical truths. In that group of sciences they placed logic and mathematics, above all because of their confidence in the success of logicism,

Principia 21(2): 209-222 (2017). 
that is, in the reduction of mathematics to logic. If such reduction were accepted, the justification of mathematical knowledge would be confined to the justification of the laws of logic. Here semantics comes into play: in short, the solution consists in understanding logical laws (for example, the principle of non-contradiction) as a not very notorious way of expressing stipulations about the meaning of the logical terms that appear in them. Thus, the truths of logic, and consequently those of mathematics, are valid in advance and cannot be denied by any experience, because - contrary to what Mill had thought — they do not affirm anything about reality.

The identification of logical and mathematical statements with expressions of linguistic conventions will present at least two problems. First, to what extent can it be said that a convention is true, at least if the same notion of truth that applies to statements that undoubtedly aim to adequately describe some aspect of reality is maintained? Second, since when we accept the law of non-contradiction, for instance, we do not learn anything about the world and we already knew how to use the terms that occurs in it, what informational value do these statements have?

The logical empiricists answered this last question in the following terms:

Thus logical propositions, though being purely tautologous, and logical deductions, though being nothing but tautological transformations, have significance for us because we are not omniscient. Our language is so constituted that in asserting such and such propositions we implicitly assert such and such other propositions - but we do not see immediately all that we have implicitly asserted in this manner (Hahn 1959, p.157)

\section{From semantics to experience and from experience to semantics}

The question remained as to whether it makes sense to say that a logical law is true when it is seen as the stipulation of linguistic conventions. Quine seems to be more than sceptical when he concludes his essay on truth by convention with these words:

But as to the larger thesis that mathematics and logic proceed wholly from linguistic conventions, only further clarification can assure us that this asserts anything at all. (Quine 1936, p.124)

This questioning was one of the first of a series of criticisms that he deployed regarding the theories of logical empiricists. Also, Quine early questioned the concept of meaning and the analytic-synthetic dichotomy. His attitude helped to erase the differences between formal and factual sciences, blocked the possibility of any form of a priori knowledge and paved the way that promised to lead to a kind of empiricism as monistic and uniform as that which Mill had tried to build. The panorama was completed with his proposal to naturalize epistemology, that is, to reject the pretension of developing a philosophy that would justify scientific knowledge, and let the results

Principia 21(2): 209-222 (2017). 
scientific research show by themselves what the virtues of scientific knowledge are and how far it is possible to know. Following the steps of Duhem's holism, the picture of scientific knowledge that Quine presented to us is as follows:

All our knowledge has a crucial point of contact with reality through the stimulation of the senses. Complex mechanisms make us conceive scientific theories that will be empirically contrasted. The disagreement between our theoretical expectations and the empirical tests must be solved by modifying some of our beliefs. They can be referred to some isolated observation, and therefore doubtful data, or to substantial hypotheses of physics, or even, if necessary, to logical principles, when they disagree with unexpected experimental results as those of quantum mechanics. The Quinean view combines empiricism with a dose of conventionalism and pragmatism. The criteria for choosing which statements we decide to keep depend, among others, on the principle of minimum mutilation. Thus, it would be extraordinary if we ignored well-confirmed observations and would be much more serious to change the underlying logic, because this later manoeuvre would transform our system of beliefs in a way that would became very difficult to manage.

In this context, according to what science suggests, Quine's empiricism gives place to ontological realism. Put succinctly: when we do science we do not doubt about the existence of everyday material objects. For the same reasons, according to Quine, we must subscribe to scientific realism; by accepting scientific theories, we commit ourselves to the entities that they postulate, even if they are not directly observable. But the most important and surprising thing for our topic is that Quine's realist attitude is projected to mathematical entities. Given the intricate relationships that integrate in a single system observational statements and theoretical hypotheses together with logical and mathematical statements, if we are coherent, we must also accept the existence of the entities that correspond to the latter, according to the principle of indispensability that Quine shares with Putnam. At this point, we realize that the primitive and basic attachment to empiricism has transformed Quine, whose aesthetic sensibility was offended by the overpopulated universes of immaterial entities (Quine 1948, p.28), in an unexpected defender of mathematical platonism.

But Quine later revised his opinions on the issue. One of the reasons for this change was the theory that he developed on language learning. According to it, he recognized a special class of sentences directly related to sensory experience as much as they constitute responses to present stimulations and called them observation sentences. This concept qualifies holism and rescues the classic distinction between theoretical and observational statements. Thus, semantic concepts that had previously been discarded can be recovered: observation sentences have a stimulus meaning and allow us to define a sort of synonymy. This is how the concept of analyticity can be recovered.

Quine's position regarding logical and mathematical truths has undergone re-

Principia 21(2): 209-222 (2017). 
markable transformations. In Pursuit of Truth (1990) he explains that, in the face of a failed prediction, scientists explore possible corrections inside the system, but among these potential modifications do not actually contemplate the abandonment of the logical laws, because they add nothing to what can be deduced from the set of extralogical hypotheses (Quine 1990, p.14). This statement sounds weird to me because I cannot understand what function logical truths would accomplish if they were not capable of influencing the set of consequences implied by the hypotheses. Anyway, Quine seems to have left behind some of his deepest differences with the tradition of logical empiricists.

A situation no less surprising is his attitude towards mathematics. Gibson had pointed out a contradiction between Pursuit of Truth and From Stimulus to Science (Gibson 1998, pp.677-678). In the first book Quine says that mathematics has empirical content, in the latter he denies it. In his reply to Gibson, Quine reaffirms the second possibility: no set of mathematical truths implies synthetic judgments of observation (Quine 1998, p.684).

In short, despite what Quine had argued at the time when he questioned the thesis of logical empiricism, later became to the conviction that logical and mathematical truths cannot be threatened by any empirical evidence. They enjoy a position different from that which corresponds to the hypothesis of factual sciences. For my part, I believe that this way Quine was recognizing the a priori validity of logical and mathematical truths.

\section{From linguistics to mathematical innateness}

In the middle of the last century Chomsky revolutionized linguistics with his hypothesis that the acquisition of language does not depend only on learning but essentially on the presence of certain innate grammatical structures. There are two types of arguments that lend in principle support to the nativist hypotheses. One is the overwhelming empirical evidence that animals know how to do many things (complicated nests or sophisticated dances, for example) without having had the opportunity of learning it. Likewise, babies carry out appropriate behaviours, such as the act of sucking, without previous education. Another argument is more modern but it complements effectively the previous one: the explanation of innate behaviours as a result of evolution by natural selection, a theory which enjoys wide acceptance in both scientific and philosophical circles.

With this background, it is not surprising that psychologists were interested in knowing whether there are other behaviours, especially cognitive ones, which can be considered as coming from an innate origin. The most serious problem was a methodological difficulty: to discriminate which part of a given behaviour can be 
considered innate and not a result of learning, it is necessary to design experiments whose subjects had not had occasion of learning how to perform that behaviour, for example, babies a few months old. Since they cannot express verbally, it is necessary to infer their mental states from motor behaviours or from some manifest attitudes, for example, some indicators of what the baby pay attention to.

One solution came from adopting an auxiliary hypothesis. Previous studies had showed that determining to what thing or situation the baby fixes his gaze and how long he keeps the gaze in the object is a criterion for the experimenter to know whether what the child perceives is something new for him or if it is in accordance with his expectations. Several experiments showed that the time a baby looks to an unexpected object or event is twice longer than when the object or situation is already known or expected by the baby. On the basis of these auxiliary hypotheses, ingenious experiments have been carried out repeatedly suggesting that babies 3 or 4 months old have already expectations related to the persistence of objects in time and space, which could be interpreted as a kind of protoprinciple of identity. For reasons of brevity I will not give more details but I will summarize the model of a series of experiments in support of the presumption that certain rudimentary mathematical operations implicit in the responses of very young babies are not the result of learning or trial and error.

The experiment is approximately like this. A baby is placed in front of a stage and he is habituated to see a single object on it, so that after repeated exhibitions he does not pay attention to the object any more. Then, a screen is placed in front of the object so that the object is hidden. Then, for the first time, the child can see a hand that places another identical object behind the screen and then he sees the hand going out without any object. When the screen is removed and the baby sees that there are two objects on the stage, his reaction (the time he keeps his gaze fixed on the situation) indicates that the presence of two objects where there used to be one does not violate the baby's expectations, in the same way that it would happen with a adult. The experience was repeated introducing up to 3 objects. The experiment was also reproduced in the opposite direction, removing objects instead of adding them, and the reactions of the babies were similar to those exhibited by an adult (Wynn 1992). All those, and other similar experiences have been interpreted as indications of a non acquired capacity for addition and subtraction of small amounts of things. Thus, the idea that the ability to perform mathematical operations has its primary origin in an innate trait acquires an interesting plausibility. After summarising different experiments carried out on animals and infants by several researchers and by herself, Karen Wynn has drew the following conclusion:

The experiments reviewed above show that human infants and other animals possess a sensitivity to numerosity, and an ability to determine the results of simple arithmetical operations. The fact that these abilities are evident in

Principia 21(2): 209-222 (2017). 
a wide range of species and at a very early age in human infancy suggests that we are innately equipped with such knowledge, rather than learning it through induction over experience (Wynn 1992, p.329)

\section{Conclusion: empiricism and psychology to the rescue of a precious treasure of the rationalists}

I confess that the proposal to naturalize epistemology to the point of dissolving it in science does not seem to me completely appropriate, for reasons that I have already outlined elsewhere. But nevertheless I believe that the outcomes of scientific research can be relevant to solving epistemological questions. Contemporary empiricists are closer to a moderate representative realism like that of Locke than to Hume's empiricism. Therefore, the results of experiments and empirically adequate theories are acceptable to the empiricist. I seem to remember that Quine once said that if irreproachable experiences showed that some people are clairvoyant, it would be necessary to recognize the phenomenon (recall Rhine's and others' controversial experiments on extrasensory perception). Well, the aforementioned empirical research about babies proves nothing about the ontological status of numbers, the truth of mathematical propositions or their foundation. But, on the basis of several types of different experiments, several authors find plausible the hypothesis that certain cognitive phenomena, and among them some very simple - logical or mathematical operations include important elements of innate origin, something like an a priori component.

Benacerraf (1973) has raised a problem about mathematical knowledge: how can the abstract entities that are the subject matter of mathematical knowledge can be known to human beings of flesh and blood if it is impossible for those entities to exert any causal relation on them? The question presupposes a causal theory of knowledge, like Locke's doctrine about the effect on the subject by external objects. But the scientific results outlined in the preceding section show that this is not the only way, and not the most correct one, to formulate the question. Apart from experience and physical causality there may be other ways of forming beliefs that, in principle, constitute knowledge: they work perfectly in our dealings with the world and are universally recognized. Nevertheless, its origins are not located in the external material objects that stimulate our senses but in our genes. Perhaps the old rationalist philosophers would make a face of resignation in front of a situation that is still paradoxical. After so many centuries, the new generations of their eternal rivals, the empiricists, seem to have discovered by just taking advantage of the own methods of the empirical sciences that innate knowledge, that is, a priori knowledge, could be more than a mere illusion.

Principia 21(2): 209-222 (2017). 


\section{References}

Benacerraf, P. 1973. Mathematical Truth. Journal of Philosophy 70(19): 661-679.

Frege, G. 1884. Die Grundlagen der Arithmetik: eine logisch mathematische Untersuchung über den Begriff der Zahl. Breslau: W. Koebner. Translated as The Foundations of Arithmetic: A logico-mathematical enquiry into the concept of number, by J.L. Austin, Oxford: Blackwell, second revised edition, 1974.

Gibson, R. 1998. Quine's Philosophy: A Brief Sketch. In: L. E. Hahn; P. A. Schilpp (eds.) The Philosophy of W. V Quine, pp.667-683. Chicago and La Salle, Illinois: Open Court.

Hahn, H. 1959. Logic, Mathematics and Knowledge of Nature. In: A. J. Ayer (ed.) Logical Positivism. New York: The Free Press.

Hume, D. 1748. An Enquiry Concerning Human Understanding. London: A. Millar.

Kusch, M. 2015. Psychologism. In: E. N. Zalta (ed.) The Stanford Encyclopedia of Philosophy. https://plato.stanford.edu/archives/win2015/entries/psychologism/.

Ladriere, J. 1957. Les Limitations Internes des Formalismes: Etude sur la signification du théorème de Gödel et des théorèmes apparentés dans la théorie des fondements des mathématiques. Paris: Gauthier-Villars.

Lemhoff, R. 2016. Intuitionism in the Philosophy of Mathematics. In: E. N. Zalta (ed.) The Stanford Encyclopedia of Philosophy. https ://plato . stanford . edu/archives/ win2016/entries/intuitionism/.

Locke, J. 1690. An Essay Concerning Humane Understanding. 1st ed. 1 vols. London: Thomas Bassett.

Mill, J. S. 1843[2002]. A System of Logic. Honolulu: University Press of the Pacific.

Quine, W. V. 1936. Truth by Convention. In: O. H. Lee (ed.) Philosophical Essays for A. N. Whitehead. New York: Longmans Green \& Co.

- 1948. On What There Is. The Review of Metaphysics 2(5): 21-38.

-1990. Pursuit of Truth. Cambridge: Harvard University Press.

- 1995. From Stimulus to Science. Cambridge: Harvard University Press.

- 1998. Reply to Roger F. Gibson, Jr. In: L. E. Hahn; P. A. Schilpp (eds.) The Philosophy of W. V Quine, pp.684-685. Chicago and La Salle, Illinois: Open Court.

Scheewind, J. B. 1972. Mill, John Stuart. In: P. Edwards (ed.) The Encyclopedia of Philosophy, Vol. V. New York, London: Macmillan publisihnig Co. Inc, \& The Free Press.

Wynn, K. 1992. Evidence against Empiricist Accounts of the Origins of Numerical Knowledge. Mind \& Language 7(4): 315-332.

Rodolfo GaEta

Universidad de Buenos Aires Universidad Nacional de Luján rodygaeta@gmail.com 